\title{
The Concept of Using Educational Computer Games in Teaching Legal Disciplines: A View from Russia
}

\author{
Aleksey Anisimov ${ }^{\text {* }}$ \\ (D) 0000-0003-3988-2066
}

\author{
Agnessa Inshakova ${ }^{2}$ \\ (D) 0000-0001-8255-8160 \\ ${ }^{1}$ Kutafin Moscow State Law University, Moscow, RUSSIA \\ ${ }^{2}$ Volgograd State University, Volgograd, RUSSIA \\ * Corresponding author: anisimovap@mail.ru
}

Citation: Anisimov, A., \& Inshakova, A. (2022). The Concept of Using Educational Computer Games in Teaching Legal Disciplines: A View from Russia. Contemporary Educational Technology, 14(3), ep365. https://doi.org/10.30935/cedtech/11808

ARTICLE INFO

Received: 26 Oct 2021

Published: 10 Feb 2022

\section{ABSTRACT}

The use of educational computer games in the context of the coronavirus pandemic is becoming increasingly popular in the educational process when studying a variety of disciplines. And if practical steps have been taken in this direction in technical, pedagogical, and some other sciences, then there is a doctrinal and practical gap in the teaching of legal disciplines that needs to be filled. The purpose of the study is to argue the prospects for the use of educational computer games at law faculties, which makes it possible to more effectively assess students' knowledge, as well as increase their motivation to actively participate in the educational process. In the course of the study, methodology involved the theoretical and practical experience of developing educational computer games in various academic disciplines was summarized, the scientific literature and the existing practice of their use were analyzed, and the possible effect of introducing educational computer games into the educational process at law faculties after the development and implementation of such games in practice, including the first-generation educational computer game developed by the authors, was modeled. The research findings indicate formulation of a doctrinal concept of the use of educational computer games, identifies three of their generations, and shows the features of the development and application of each of them, including the author's experience in developing a training computer game by right of the first generation. The authors analyzed the technical problems associated with the development of educational computer games and suggested ways to solve them. The authors' proposals can be used by universities in any country to interact with game design studios to develop educational games.

Keywords: computer, games, education, skills, knowledge

\section{INTRODUCTION}

The coronavirus pandemic which has caused huge human losses and serious losses for the economies of most countries of the world has also spurred long-standing discussions about the ways and means of digitalizing education. The essence of this problem is significantly broader than the issues of preserving the health of students or solving the technical issues of organizing training on various Internet platforms (Zoom, Teams, etc.). Modern higher education in Russia and many other post-Soviet countries have faced a more serious systemic crisis, associated with a sharp drop in the attractiveness of higher education for young people and their parents (Erokhina, 2016; Sushchenko, 2016). According to sociologists,

"the percent of Russian parents who want to send their children to universities has fallen by half in ten years. When asked where their children will continue their education after school, one in five parents $(21 \%)$ said that this will be secondary vocational education. In 2010 , only $8 \%$ of the respondents chose this answer option. In 2021, 43\% of the parents said that their children would

Copyright ( $\mathbf{2 0 2 2}$ by authors; licensee CEDTECH by Bastas, CY. This article is an open access article distributed under the terms and conditions of the Creative Commons Attribution License (http://creativecommons.org/licenses/by/4.0/). 
go to university after school. In 2010, there were 80\% of such parents, in 2015-55\%, and 2020-48\%" (Proshina, 2021).

Accordingly,

"in 2021, this answer has been given by $5 \%$ fewer respondents than in 2020 . There has not been such a sharp drop in the popularity of universities since 2016 . Another $2 \%$ of parents said that their children would go to work after school (the same percentage was in 2010), and the rest of the school graduates have not decided yet" (Proshina, 2021).

The continuation of this trend will inevitably lead to the reduction in the number of universities and their graduates and will reduce the number of highly qualified specialists necessary for the development of the economy, social sphere, culture, and other vital sectors of public life. Undoubtedly, this problem is caused by a complex set of factors (economic, political, etc.), whose full analysis goes beyond the scope of the goals and objectives of this paper. Meanwhile, one of these reasons is the archaic organization of the educational process, which has not changed in Russia since the mid-XIX century, limited only to the class-and-lesson system, which is not interesting for young people.

One of the options for the form of knowledge transfer moving away from the familiar to the older generation of teachers, to the one which is understandable and interesting for young people in the development and implementation of educational computer games on law in the educational process. In this case, the training process will take the form of a computer game familiar to student youth (18-25 years old), but its content will meet the requirements of the state standards, and serve the purpose of mastering the serious theoretical and practical material.

Thus, the purpose of the study is to substantiate the need for theoretical development and subsequent practical implementation of such a manifestation of digitalization as the development of educational computer games. In the article, the authors prove the advantages of using this method of assessing students' knowledge at university law faculties, trends and prospects for the development of educational computer games in law (from a relatively simple first generation to the second and third, requiring more in-depth study, both in terms of teaching methods and new technical solutions of game design studios). The article also analyzes the importance of educational computer games in responding to new challenges facing modern higher education, and possible technical solutions that contribute to the development of educational games. Given the scale and complexity of this problem, the authors do not pretend to its final solution, and therefore offer two main theses for discussion: firstly, a discussion of the importance of computer training games for the educational process of law faculties, and, secondly, they propose to discuss their developments in this area, their applicability to the assessment of students' knowledge of environmental law, the possibility of using the first generation of computer training games for all academic disciplines in law.

\section{LITERATURE REVIEW}

The problem of using digital technologies in the higher education system has long been of interest to scientists around the world, including the Russian Federation. At the same time, one of the most discussed issues in the scientific literature is the problem of the terminology used. Thus, Kovtunenko (2019) draws attention to the efficiency and comfort of providing information and communication services. Moskalyuk (2019) suggests considering the processes of digitalization of education in the context of the labor market transformation and the need to replace the methodological base of training, which will allow to form the skills and abilities of school children and students that are currently in demand.

Burlutskiy (2020) points out the importance of creating the Internet environment, the need to improve digital literacy, use digital technologies, digitalize the processes of organizing the educational process and testing knowledge, and create digital content. No less interesting is the opinion that the digitalization of education is the introduction of the distance learning technologies and other elements of distance learning (Loginova et al., 2020) into educational processes, while the emphasis on technologies is now very widespread in the scientific doctrine when discussing this issue (Yuzhakov \& Efremov, 2018). 
Recognizing the scientific value of the above points of view of Russian scientists, it should still be noted that they focus only on the formal aspects of digitalization of education, namely, the development of distance technologies, improving digital literacy, as well as some other technical and methodological aspects of the problem. A critical analysis of the above points of view allow us to conclude that the digitalization of education involves not only a formal but also a meaningful change in ideas about the trajectories of further development of education. This means the formation of a fundamentally new model for the provision of educational services, facing the student. Such an approach will mean taking into account the current lifestyle of young people, abandoning outdated teaching methods, forming new competencies for students at law faculties to process and generalize huge information flows, without which they will not be able to work effectively in the new changed digital world. This is the main content characteristic of the digitalization of education, both in Russia and in other countries of the world.

The Russian government had a general understanding of this trend even before the coronavirus pandemic, which was reflected in both the regulatory documents and the scientific doctrine. In particular, the works of Dneprovskaya (2018) analyzed the trends of providing the universities with computers and Internet access, stated the problem of automation of administrative and educational processes. Other authors, even before the pandemic, drew attention to the insufficient qualifications of university teachers in terms of information technology (Sayapina, 2020) demanded the changes in the content and organization of educational courses, and improved the quality of administrative and educational processes (Kivarina et al., 2018).

Even before the pandemic, there was a clear understanding that in the twenty-first century, the main value is not the natural resources, but human capital, which consists of three components: the capital of education, health, and culture (Popov \& Popova, 2018). Accordingly, education can also act as a source of economic growth. However, even in this case, the statement of individual shortcomings in the field of digital qualification of teachers, automation of educational processes, or lack of computers at universities is a rather superficial look at the problem under consideration. It seems that the introduction of modern digital technologies into the educational process at law faculties should take place in stages, and if we are talking about educational computer games, then also voluntarily. It is necessary to create material or moral incentives for teachers who have decided to organize their implementation, and only in this case, the expected effect will be obtained.

\section{METHODOLOGY}

Speaking of methodology, it should be noted that the scientific literature pays great attention to the use of computer games in the learning process in kindergarten (Shchelkunova \& Kalmykova, 2016), school (Shirinkina \& Lobasheva, 2020), as well as individual (non-legal) academic disciplines of the universitymathematics, foreign languages, computer science, and some others (Bodrova \& Trubaichuk, 2012; Gizutdinova \& Razumova, 2018; Shabalina, 2010). This experience of practical implementation of educational computer games in the educational process has been studied in detail by the authors, however, it should be noted that in each of these disciplines there is a very significant specificity of the preparation of such games (both in terms of the scenario and theoretical or practical skills to be developed/controlled following the plan of the game developers). In this regard, it should be noted that the lack of experience in the implementation of educational computer games at the law faculties of the Russian Federation suggests that this experience has not been in demand today and has been translated into practical terms. The authors tried to do this first, using some methodological ideas of representatives of other branches of scientific knowledge and offering many didactic and technical solutions for the first time.

Concluding this section, we note that during the writing of the article, scientific works and practical developments of representatives of technical sciences related to the development of computer engines and programs used to create computer games were used (Sanders, 2017; Shaidurov, 2018; Tazabekov \& Buzhinskaya, 2020). However, in all the works that were used in writing this article, it was either about the development of entertainment games or about the features of using computer engines and programs, without taking into account the specifics of the learning factor, which is the basis of the computer games offered by the authors by right. Thus, these developments were used by us only in the part that was relevant 
to the subject of our research. It was not possible to find directly scientific articles and monographs that would reveal this aspect of computer technology in Russian libraries and the Internet.

\section{RESULTS AND DISCUSSION}

The announcement in March 2020 of the transition of Russian higher education to a distance education system in connection with the pandemic showed that neither the education authorities nor the teachers and students were ready for a sharp change in the usual formats of educational activities. Nevertheless, in the shortest possible time, all law faculties of the country were transferred to the remote form of work using Moodle, Zoom, and Teams platforms; the development of new methodological support began, and there was, although painful (from the point of view of psychology), but still constructive development of the new opportunities for digital education. In the conditions when the peak of the pandemic in Russia has passed (the spring of 2021), a return to the previous "pre-COVID format" of teaching has not even been discussed. The universities have retained the remote form of lectures, returned students to the classroom for seminars (while maintaining the face mask mode), while during the seminars it is possible to use certain elements of remote work that hasn't existed before (for example, the ability to solve law tests on the Moodle platform).

However, the main outcome of the pandemic has been the continuation of the discussion of the strategy for the development of higher legal education in the following aspects:

1. Even before the pandemic, the digital technologies for drawing up certain types of civil contracts began to be implemented in Russia, which led to a discussion about the possible death of the legal profession. Meanwhile, it should be about changing the set of competencies of the graduate required by the employer (the skills of communicating with the public authorities on the Internet, the skills of online filing of various claims, applications, and appeals, the skills of consulting citizens using the digital platforms Zoom or Teams, the ability to use a digital signature and knowledge of the basics of cyber security, the ability to conclude smart contracts, maintain online registers, etc.).

2. There is a change in the format of teaching; students have access to lectures and other developments of teachers. This is another consequence of moving away from the outdated format of the classroom system and expanding the skills of independent work of students but requires strengthening the legal protection of the copyright of developers of ordinary textbooks (training aids), as well as online programs and courses. This will be especially important when the universities conclude agreements on network interaction and data exchange.

3. It is necessary to introduce in all Russian universities the procedures which are common in some countries for determining individual trajectories of students' education, to ensure their real choice of the subjects they study, to develop an interdisciplinary approach and to develop special training courses that reflect the specifics of modern digital technologies. This will reduce the cost of training but will require additional costs for the digital training of teachers and the purchase of equipment.

4. Finally, one of the manifestations of the new strategy for the development of higher education in the field of digital technologies is the development of educational computer games that allow both improving the assessment of students' knowledge and developing some useful digital skills and abilities.

\section{Meaning \& Classification of Educational Computer Games (Serious \& Entertaining Games)}

The traditional games have existed among all the peoples of the world throughout the history of mankind, playing a key role in the development of the national education systems. However, the 21 st century has given rise to a new mechanism of interaction between the human and the game, which was caused by the digital revolution. The advent of the digital revolution brought with it computer technology, which quickly became open to a large part of humanity (although the problems of the digital divide and inequality persist to this day). The new generation of the Internet games that followed these technologies soon offered new, engaging ways for people of all ages, genders, cultures, and races to communicate and interact around the world. As a result, the global computer game market was estimated at the US $\$ 162.32$ billion in 2020 and is projected to 
reach US $\$ 295.63$ billion by $2026^{1}$. In the most general form, the classification of computer games can include entertaining and serious games. Serious games are games for teaching and learning different disciplines. A serious game that is used in the educational process is also called an "educational game". The differences between serious and entertaining games are that serious games are focused on solving an important social task, contain thoughtful elements of learning, and contribute to the development of practical skills or the consolidation (verification) of the acquired knowledge. Serious games can be used in a wide variety of sectors of public life, allowing you to simulate and "play" a variety of life situations, from school education to business and military affairs. It should be agreed that serious computer games allow students to very efficiently learn new educational material excitingly, acquire the necessary skills, and consolidate the existing knowledge (Duminsh \& Zaitseva, 2016; Turpak, 2016). As noted by Ahmad and Jaafar (2012), eight of the eleven studies conducted showed that the quality of knowledge is better in game-based learning, while the other three studies did not reveal a significant difference. Seven of the eight studies of the student interest in learning suggest a preference for games by students (Ahmad \& Jaafar, 2012). The results of these studies are also directly related to higher legal education, in which the goal of a training computer game should be to take advantage of the usual form of information and leisure activities for young people to acquire the learning skills necessary for a modern lawyer, as well as to test the acquired legal knowledge.

The advantages of serious games are the possibility of solving real legal problems in a virtual form, learning through taking risky decisions, and immediate feedback. The prospects of the computer industry, including graphic design (Bulander, 2010), depend on the development of serious games. However, this is where certain difficulties arise. The development of such a game focused not on a standard computer or laptop, but on a mobile phone, presents a certain difficulty for the game designer, since the capabilities of mobile devices are limited in terms of memory, screen size, input, or control interfaces, which can create obstacles to the usability of the phone for such a game. Another obstacle is that at the moment in the world of social science, the discussion about the dangers and benefits of computer games for young people does not stop. On the one hand, it is recognized that computer games can contribute to the development of intellectual skills; it is an excellent means of spending leisure time and preparing young people to become successful workers and citizens in the twenty-first century. On the other hand, the representatives of the older generation reasonably believe that the excessive interest in computer games can contribute to the growth of consumer sentiment, occupy too much attention of school children and students, and even contribute to the growth of aggression and violence among young people (Williamson, 2009).

According to the authors, regardless of the current state of this discussion, the development of digital technologies in the education system of any country is inevitable, since modern students have grown up with laptops, iPhones, tablets, and want to use this everyday technology, including in the learning process. This desire also meets the interests of the state, which strives to build the most efficient and modern model of higher education. Therefore, the higher education system will inevitably change, primarily as a result of the introduction of modern digital technologies. Meanwhile, in the scientific literature that studies the use of computer games in the educational process, a lot of publications deal with their role and significance in school or at the preschool level. Much attention is also paid to the possibility of using computer games in teaching foreign languages as well as individual academic disciplines (mathematics, computer science, etc.). At the same time, the possibilities of using computer games in the course of teaching legal disciplines have not received proper doctrinal research and practical testing.

\section{Development of the "First Generation" Educational Computer Game: Problems \& Prospects}

The simplest model of a learning computer game on law involves testing in an academic discipline (for example, environmental law) not just in the form of solving a test on a computer screen, but in an original game form. The use of such technologies will increase the student's motivation to study a particular academic discipline, diversify the educational process, promote better assimilation of the material, turn the student from an observer into a direct participant in the educational relations, and allow the formation of some useful legal skills. The development of educational computer games, in addition to directly solving the problems of

1 Gaming market-Growth, trends, COVID-19 impact, and forecasts (2021-2026). https://www.mordorintelligence.com/ industry-reports/global-games-market 
mastering (or controlling) legal skills, also solves several auxiliary tasks related to creating an emotional atmosphere favorable for learning, removing psychological barriers to learning, improving communication among students, as well as with the teacher, is an important source of self-education skills which are necessary for a lawyer. To date, of all types of computer games, the most promising ones, in terms of achieving the goals and objectives of teaching students at law faculties, is an adventure game (quest).

Quests as one of the main genres of intellectual adventure computer games appeared in the second half of the 70 s of the last century and enjoyed popularity throughout the next decade. They are an interactive story with the main character, controlled by a player or several players, who must find solutions to the tasks, set in unexpected situations to achieve the goal. Mental tasks in ordinary computer games-quests are a puzzle with different solutions. For pedagogical purposes, this genre has attracted attention by the fact that in the course of the game, its participants acquire certain knowledge and skills, gradually completing certain problem tasks (Gafiullina, 2018).

The most promising model for the first stage of the introduction of computer games in the Russian educational space (including at law faculties) is the quest model associated with the assessment and control of the student's knowledge, which is easiest to organize by conducting a final (test and exam) or intermediate testing in the form of a game (which is very important in the context of distance learning). Creating computer games that allow you to simulate complex group actions is a matter for the future. Guided by such considerations, the authors of the paper attempted to develop a training computer game on environmental law, during which they encountered the following problems:

1. The preparation of a legally significant game scenario. For the success of an educational computer game, it is necessary to "create a legend, a story equipped with the dramatic plots that accompany the learning process. This helps to create a sense of belonging, contribution to the common cause, and the interest in achieving educational goals" (Polyakova \& Kozlov, 2015). Based on this, the authors have developed the following storyline, which has legal significance.

The first part of the game is a Prologue. This is an introductory level that explains the plot, the basics of character management, and the goals facing the player. Developed by the authors educational computer game begins with a screen saver about how a student Ivanov (Appendix A) witnessed an environmental crime-illegal logging by a group of persons by prior agreement.

The second (main) part of the game is that the student decides to report this violation of the environmental legislation to the environmental Prosecutor's Office. To do this, he/she must climb three routes to the 30th floor of a large house, while three offenders will be waiting for him on each floor and ask him questions in the form of tests. If the answer is correct, the player goes up one floor, if it is incorrect, he is dropped one floor down. The number of incorrect answers is limited (no more than 10). The maximum duration of the game is 45 minutes.

The third (final) part of the game. If a student reaches the 30th floor and informs the environmental prosecutor (his appearance is shown in Appendix B) about the illegal logging, he will receive a reward (the prosecutor presents him with a certificate of honor "The Defender of the Forest" and informs him that he has passed the test).

The final shot is of three fairy-tale delinquent characters sitting behind bars. If the student fails to reach the 30th floor (more than 10 mistakes or the time expires), a plot with a logging truck leaving for the border appears on the screen. The number of the test questions is 90 , with four possible answers in each. This number is because the computer game assumes 30 floors, with three questions for each floor. Here is a typical example of such a question: Permits for emissions and dumping of radioactive substances are issued by ...

a. The Ministry of Internal Affairs of the Russian Federation

b. The Federal Service for Supervision of Natural Resources

c. The Federal Service for Environmental, Technological, and Nuclear Supervision

d. The Ministry of Civil Defense, Emergencies and Disaster Relief of the Russian Federation

2. Ideally, the three ways up for the positive hero of the quest should differ in the degree of complexity of the test questions (each floor has more complex test questions), but in the first version of the 
training computer game currently being developed, this has not yet been done. The introduction of this parameter will be made later, as receive the information about the results of the students' game testing. The importance of this complication of the task of organizing the testing in a computer game lies in the fact that the analysis of its results is the most important "feedback", allowing you to determine which topics of the training course were learned by the students better or worse, and then make some adjustments to them. At the same time, an additional option used in various games with a hint to the student (if he/she cannot give the correct answer, h/she can ask for the "negotiations", during which the game character can lead him to the correct answer or even count a partially correct answer) (Virvou et al., 2018) does not seem to be a very successful solution in given case, since at this level of complexity of educational games, such a strategy will lead to a decrease in the efficiency of evaluating the students' knowledge, put them in an unequal position, and make it difficult to evaluate objectively.

The latter circumstance has long been in the focus of attention of the developers and users of educational computer games, being part of a more complex problem-evaluating the efficiency of such games. In the world of educational science, attempts have already been made to build a certain rating scale that allows teachers to choose only good games for use in their classes. In this regard, various authors proposed to focus on the categories of pleasure (from the game of students), usability, the achievement of learning goals and objectives (through the knowledge assessment), and some others. Oguz (2012), in particular, offers 51 points for evaluating the efficiency of educational computer games in three categories: the achievement of learning goals, fun, and usability.

In terms of usability evaluation, the most popular method is the method of testing and verifying the quality of the game (the heuristic evaluation). This method involves the game experts ( 3 to 5 people) checking the interface design for compliance with the established principles of the game quality to identify the potential problems of its use. This method can be cost-effective and should be carried out at an early stage of the game design. He suggests that the experts inspect an unfinished game when the game prototype is not ready yet. This method will save you from future problems with the use of the game, but at the same time, it is quite expensive, time-consuming, and resource-intensive (Nur Marissa \& Roslina, 2019).

With the Russian reality, its use is currently impossible because there are almost no developers of training computer games in the field of law in the country, and it will be difficult to provide a highquality expert assessment. It follows that for the assessment of the first level of educational computer games, the most effective in the Russian conditions will be two main criteria-pleasure (a comprehensive assessment of the game by students-the interface of the game, the correctness of the test questions, the presence/absence of the program failures during the game, etc.), as well as the degree of achievement of the learning goals (checked by analyzing the correct and incorrect answers of the students, which entails either adjusting the seminar plans, developing new learning tasks, or clarifying the questions and answers of the test itself if their ambiguity is found out).

\section{Development of Educational Computer Games on the Law of the Second Generation: A Doctrinal Approach}

The next level of development of educational computer games in the future will be the development of the 2nd generation of games for law students, which involve not a single, but collective action. If in the previous generation, the player passes all the tasks alone, then within the framework of this game, three players must perform actions synchronized in time and space. The plot of this game is that three entrepreneurs need to get a lease on a land plot and a permit to build a shopping center on the outskirts of the city. To do this, they apply to the city administration (city hall) but face bureaucratic obstacles. To overcome them, they must perform some actions.

The game begins with three players running up to a wall (the speed of their movement is set by a computer program), on which five types of tasks are placed (a total of 10 walls, each type of task is presented twice). The first type of task is the tests on land law. Each player has their test question. As a sample, you can offer the following option: 
1. When renting a land plot that is in state or municipal ownership for a period of more than ... the lessee of the land plot has the right, within the term of the land plot lease agreement, to transfer his rights and obligations under this agreement to a third party, without the consent of the lessor, subject to his notification.
a. one year
b. two years
c. five years (correct answer)
d. ten years

Accordingly, if one of the players answers incorrectly, then all three fail one level lower, and if all three answers are correct (the time to think about the answer is limited to 15 seconds), then the players move to the next level of the game. At this level, a crossword puzzle opens for each of the players, in which they must fill in the empty windows. As an example of a question, we can offer the following: What is the name of the system of the state supervision of the land fund status? (the correct answer is monitoring). If the cells are filled correctly, the players move to the third level, where each of them opens a table (two columns, five rows). The task is to choose which of the five authorities listed in the left column reports to the bolded executive authority listed in the right column (for example, the Ministry of Natural Resources and Ecology reports to the Government of the Russian Federation). To answer the question, the player clicks on a special arrow. The fourth level of this game involves working with maps or other graphical objects. For example, the player must choose from three drawings the one where the easement is shown. Finally, at the fifth level of difficulty, the player runs up to the big screen, where he is shown a film or news clip, and he must give a legal assessment of the plot he saw (for example, the qualify the actions of the film hero as a criminal act of damage to the land). Such "digital stories" (short videos) have been frequently used in the social sciences since the early 90s, improving educational communication (Rozanova, 2020).

Within this group of educational computer games in the field of law of the 2 levels of difficulty, there can be two types of plot. In one of them, described above, three players move with the speed set by the program, and at the same time solve one type of task. The second model of the game assumes that each player moves along their trajectory, entering different rooms (something like it is done in the game Among Us), and independently chooses one or more questions of varying degrees of difficulty. And if all three players have scored the required number of points in 2 minutes, they move to the next level. In other words, you can answer 10 tests in two minutes and score the required number of points, or you can watch 1 film clip and score the same amount. Each player chooses their strategy (they can agree on this in advance). However, if the total number of points is not enough (for example, one of the players made a mistake), - all fall to the level below. The advantages of both versions of such a team game are that it allows you to form the skill of overcoming difficulties, the ability to communicate in a team, the skill of social interaction. This allows you to develop logical thinking, more deeply study the academic discipline (in our case, "land law") so as not to let your friends down, promotes hand coordination, visual perception, and memory, organizational skills, develops the ability to make quick decisions.

\section{Prospects for the Development of Educational Computer Games on the Right of the Third Generation}

The third generation of educational computer games is business simulation games, which involve simulating real legal situations (for example, court sessions), which is more effective than using computer games only for knowledge assessment. The business game is based on an imitation model of real professional activity. The participants of the game in the simulated conditions are assigned roles and perform the specified actions following the instructions. By solving the problems inherent in the situation, the players acquire the subject knowledge. This method has shown positive results in the teaching of university disciplines, since

"the game form of classes and the use of various elements of the game contribute to the development of the educational and cognitive activity of students, increase attention, mobilize efforts aimed at solving problems, allowing you to feel a sense of success and believe in your strength" (Karauylbaev, 2012). 
About the conditions of Russian law faculties, this type of computer game involves simulating a court session for the consideration of a civil case, and here a certain difficulty is the selection of an educational task. One of the possible options here may be the plot of the case related to the legalization of unauthorized construction.

This choice is because, for the legalization of an arbitrarily erected real estate object, a complex of procedural actions is required, related to the appointment of the expert examinations, the interrogation of witnesses, the application of various petitions, etc. (Goryushin, 2020). All this will allow us to provide the necessary level of complexity and variability of the consideration of this case. As a result, the process can develop in several possible directions, and at each subsequent stage, the number of new options for the development of the events will only increase. However, only one decision can be correct, all the others will be wrong for a particular player. At the same time, it is very important to lay down such an option that even if you move along the wrong path, the player will be able to "jump" to the correct trajectory. The options for the development of the events are presented in Appendix C. When preparing such a game, the experience of the developers of the game "Detroit: Become Human" can be taken into account, in which each of the acting characters has their storyline, and depending on the decisions made by the players during the game, the further development of the exciting plot is determined ${ }^{2}$.

In given case, three students will participate as players-a representative of the defendant (a citizen who erected the unauthorized building without the permission of the government), the plaintiff (a local government body demanding the demolition of the building), and the judge who decides on the case. The choice of this category of cases makes it easier for the game developers, since there are quite a lot of such cases in the judicial practice of Russia, and there are serious scientific studies of various aspects of their hearing. In the future, when developing this type of educational computer game of the 3rd generation, it will be advisable to plan the use of virtual computer helmets (or glasses), which have their specifics. Virtual reality is one of the directions of further development of electronic learning tools and means the technology of immersing the user in a three-dimensional (3D) interactive environment of the studied phenomenon (process), with the ability to interact with other objects in the virtual environment (Goncharova et al., 2017; Yadrovskaya, 2015). These technologies of "immersion in the environment" are already widely used in sports, physics, medicine, military affairs, and other sectors.

The implementation of this technology will allow students to recapture the very atmosphere of the court session, provide a sense of a real "participation effect", the opportunity to see the audience and read various documents, but today its implementation is difficult for the technical and financial reasons (Ablyaev et al., 2016).

\section{Technical Problems of Developing Educational Computer Games on Law \& Ways to Solve Them}

At the moment, the authors of the paper are developing a training computer game of the 1st generation ("The Defender of the Forest"), since others require too much time and effort. When preparing this type of computer game, the authors were faced with the question of what kind of engine will be used in it. Among the most promising options were three engines: CryEngine developed by the company "Crytek", Unity developed by the company "Unity Technologies" and Unreal Engine 4 of the company "Epic Games". The authors studied each of them, trying to figure out which engine would suit our game best.

The authors gave up on the idea of using CryEngine almost immediately, because there is too little documentation for this engine, and it is the least suitable for a small development team. In addition, it had some performance issues that made it unsuitable for small projects; its toolset looks cumbersome compared to all available competitors, and its gameplay structure is extremely inflexible. In addition to all this, recently Crytek has stopped paying enough attention to providing documentation or training resources for the development of its community, and most of the available information about its engine is outdated. As a result,

2 See the official website of the developer of this game-the French company Quantic Dream. https://www.quanticdream.com/en\#!/en/category/detroit 
using this type of game engine by a small team, with almost no help from more experienced colleagues (or advice on the forum), to discuss creating our game with this set of tools, would not have led us to success.

In this situation, the authors decided to turn to the option with the Unity (Ershov, 2020; Shaidurov, 2018) engine. Unity is a professional multi-platform 3D game engine and integrated powerful game editor for creating games; it resembles a game designer, as it is an editing environment with a user-friendly interface (Tazabekov \& Buzhinskaya, 2020).

This engine initially seemed very preferable to us, especially given the huge audience of developers and forums with its discussion, excellent documentation, and low entry threshold. However, with a deeper study of this issue, the authors still came to the conclusion that this engine is most suitable for creating small 2D games, and the greatest bias in this engine can be traced towards mobile games, and our goal was a fullfledged 3D computer game. In addition, to use Unity, you need to know the C\# programming language, which the authors have not yet mastered at the proper level.

As a result, for the development of our educational computer game of the 1st generation "The Defender of the Forest", the authors chose Unreal Engine 4 (Sanders, 2017), whose first modification was created by Epic Games in 1998. It was one of the first game engines with excellent functionality: it combined a graphics engine, a physics engine, artificial intelligence, file and network system management, and a ready-made development environment for games. Given the level of performance of most computers at that time, the developers somewhat simplified a number of elements of the engine: a collision detection system, the network code, a controller code for the player. Using the Blueprints (Tran, 2017) system in the game 3 . Blueprints is a visual programming system based on the Unreal Engine 4 engine, which does not use a single line of code. This system is a quick way to both create game prototypes and be able to make and finish a fullfledged project using only the specified system. Instead of writing a line-by-line code, you can do everything visually: drag the nodes, set their properties in the interface, and connect their "wires" (we displayed this problem in Appendix D).

In addition to quickly prototyping the game, Blueprints also makes it easier for non-programmers to create scripts. It is also very valuable to be able to use the engine for free until the game starts to bring a significant profit. The fact is that starting from May 13, 2020, the company "Epic Games" officially announced the refusal of its part of the royalties for the games developed on Unreal Engine 4, until the developers earn their first income of $\$ 1$ million. Finally, the choice of this particular engine (Unreal Engine 4) was because it offers highquality visual effects immediately as a default, while, for example, the Unity game engine-although it can create high-quality visual effects-requires much more work to ensure that the graphics quality is close to the same level as on Unreal Engine 4. But even then, the quality will not always be as high.

\section{Recommendations for the Development of the Use of Educational Computer Games}

1. The use of educational computer games cannot be the main means of learning-it only complements the traditional forms and methods.

2. The introduction of games in the educational process allows you to solve several tasks: to check (control) knowledge; to form the skill of working in a group, responsibility and mutual assistance; to learn how to make the right legal decisions in a game situation as close as possible to practice.

3. The development of educational computer games should be based on the following principles: the interaction of players; the correlation of the complexity of tasks to the knowledge of students; the development of the game design that meets the requirements of students; the providing of feedback; the recognition of characters; the clear instructions on the goals and objectives of the game, its practical orientation.

4. It is very important when developing educational computer games in the field of law to think through the drama-the scenario of the game, which should be based on the national cultural and legal traditions, meet the mentality of the student players, and be developed based on modern learning theories (Amory, 2003).

${ }^{3}$ Visual Script Blueprint. https://docs.unrealengine.com/en-US/ProgrammingAndScripting/Blueprints/index.html 
5. In contrast to the development of commercial games that take into account the gender, experience, or age of the player (Ibrahim et al., 2017) in our case it does not matter in principle.

6. According to the scope of application of training games, it is necessary to distinguish between certification (verification, test), production games (simulating trials and other practical legal situations), research games (involving the development of conceptual strategies and solutions).

7. It is unacceptable to use the elements of violence (shooters) or gambling when developing training games (for example, to make a training game in the form of a casino game, awarding points for correct answers to questions).

\section{CONCLUSIONS}

The coronavirus pandemic that hit the world in 2020-2022 divided the development of the education system into "before" and "after". To preserve the health of teachers and students, most universities in the world were forced to dramatically switch to new digital standards in the education system. At the same time, in different countries and universities in the "pre-crisis period", different successes were achieved on this path, and different strategies for the development of digital technologies were developed.

Even during the pandemic, the discussions among experts inevitably intensified about what new digital technologies are required for distance learning of students, what their efficiency is, and how to further improve them. Admittedly, one of these technologies is the development of educational computer games in the field of law, which in Russia is still at the very first stage of development (the discussion stage). At the same time, there is already an interesting experience of using educational computer games in the field of learning foreign languages, computer science, mathematics, and some school disciplines. This experience is of interest both in the technical part and in solving didactic problems. Of all the genres of educational computer games that exist today, we consider the use of the quest (adventure game) as the most promising. One of the first such law games ("The Defender of the Forest") is currently in development (Unreal Engine 4).The mass development of such a modification of law games (for example, with the help of grants) will increase the efficiency of seminars, since it involves greater involvement of students in the essence of the legal phenomena and processes that are taking place, and gives them greater dynamics and efficiency, especially in the context of distance learning. Even more preferable is the use of such games for taking credits. As the first modification of educational computer games is introduced into pedagogical practice, it will be possible to develop their second (group games related to solving educational problems) and third (trials, including using virtual helmets) generations. The appearance of the last two types of educational computer games cannot happen quickly due to several objective reasons-starting with the high cost of their development and ending with a lot of technical difficulties, since their creation will require specific knowledge, both in the field of law and in the field of game design. The development of this type of quest is only possible if there is long-term contact between the representatives of legal science and the game industry. At the same time, difficulties are inevitable with the development of a detailed scenario for such a game, a competent formulation of the technical task (which must be executable). If such solutions are found, it will help to improve the image of the university, increase its competitiveness, and attract a large number of applicants.

In the case of state recognition of such a direction of digitalization of legal education as promising, the education authorities can prepare a framework strategy of actions that allows for the gradual implementation and financing of this direction, with clear regulation of the goals, objectives, quality assessment and expected consequences of its implementation.

Author contributions: All authors were involved in concept, design, collection of data, interpretation, writing, and critically revising the article. All authors approve final version of the article.

Funding: The work was supported by Russian Science Foundation (Project No. 20-18-00314).

Acknowledgements: The authors would like to thank Pavel Anisimov, BSc. degree graduate of Academy of Performing Arts in Bratislava Faculty of Film and Television in the Slovak Republic (Filmová a Televízna Fakulta VŠMU v Bratislave), a specialist in 3D and animation, for technical and creative advice on theory of computer games, allowing him to formulate a conceptual understanding of meaning and options of the using computer games in Russian law education.

Declaration of interest: Authors declare no competing interest.

Data availability: Data generated or analyzed during this study are available from the authors on request. 


\section{REFERENCES}

Ablyaev, M. R., Ametov, F. R., \& Mevlut, I. S. (2016). Opportunities and limitations of virtual reality technology as a means for everyday use. Information and Computer Technologies in the Economy, Education and Social Sphere, 3, 115-116.

Ahmad, I., \& Jaafar, A. (2012). Computer games: Implementation into teaching and learning. Procedia-Social and Behavioral Sciences, 59, 515-519. https://doi.org/10.1016/j.sbspro.2012.09.308

Bulander, R. (2010). A conceptual framework of serious games for higher education-Conceptual framework of the game INNOV8 to train students in business process modelling. In Proceedings of the International Conference on e-Business (pp. 95-100). Athens, Greece. https://doi.org/10.5220/0003033300950100

Burlutskiy, A. N. (2020). The fourth industrial revolution in the context of the implementation of digital education and new ways of organizing the educational process. Academic Bulletin of the Rostov Branch of the Russian Customs Academy, 1, 123-128.

Dneprovskaya, N. V. (2018). The assessment of the readiness of Russian higher education for the digital economy. Statistics and Economics, 15(4), 16-28. https://doi.org/10.21686/2500-3925-2018-4-16-28

Duminsh, A. A., Zaitseva, L. V. (2012). Computer games in training and technologies of their development. Educational Technologies and Society, 15(3), 534-544.

Erokhina, E. A. (2016). Russian University as an instrument of "soft power" in the conditions of higher education reform. Philosophy of Education, 6, 95-103. https://doi.org/10.15372/PHE20160609

Ershov, T. A. (2020). The review of the Unity game engine. Modern Science, 8(2), 288-291.

Gafiullina, K. N. (2018). Educational quests in teaching a foreign language. Bulletin of Kazan Branch of Russian State University of Justice, 14, 369-376.

Gizutdinova, D. R., \& Razumova, O. V. (2018). Computer learning games in mathematics lessons. In Mathematical education at school and university: Innovations in the Information Space (MATHEDU 2018). Materials of the VIII International Scientific and Practical Conference (pp. 64-68). Kazan, Russia.

Goncharova, M. V., Dydrov, A. A., \& Lapteva, U. V. (2017). Virtual reality tools in the context of education. Society and Power, 5, 14-19. https://doi.org/10.22394/1996-0522-2017-5-14-19

Goryushin, V. S. (2020). The features of the appointment of forensic expertise in the civil process. Civil Law: Law and Process, 2, 84-86.

Karauylbaev, S. K. (2012). Computer educational and business games as a method of training future specialists. Bulletin of the Peoples' Friendship University of Russia. Series "Psychology and Pedagogy", 4, 159163.

Kivarina, M. V., Sazhneva, L. P., \& Borisova, I. A. (2018). The adaptation of the higher education system to the conditions of the digital economy. Bulletin of the Institute of Economics and Management of NovSU, 2, 4653.

Kovtunenko, L. V. (2019). On the problems of digitalization of education in educational institutions of higher education. In Actual Problems of the Activity of the UIS Divisions: A Collection of Materials of the All-Russian Scientific and Practical Conference (pp. 177-178).

Loginova, A. S., Odinokova, A. V., \& Gavrilova, V. E. (2020). Introduction of digital technologies in educational processes: Theory and practice. Bulletin of VSU. Law Series, 4, 317-331.

Moskalyuk, V. S. (2019). The concept and essence of digitalization of the education system. Science and Education Today, 10, 15-18.

Nur Marissa, V. S., \& Roslina, I. (2019). A review of heuristics evaluation component for mobile educational games. Procedia Computer Science, 161, 1028-1035. https://doi.org/10.1016/j.procs.2019.11.213

Oguz, A. (2012). A game scale to evaluate educational computer games. Procedia-Social and Behavioral Sciences, 46, 2477-2481. https://doi.org/10.1016/j.sbspro.2012.05.506

Polyakova, V. A., \& Kozlov, O. A. (2015). The impact of gamification on the information and educational environment of the school. Modern Problems of Science and Education, 5, 513.

Popov, Y. A., \& Popova, Y. A. (2018). Digitalization of higher education as a promising direction in the formation of human capital-The youth policy of Russia in the context of global world changes. In Proceedings of the International Scientific and Practical Conference (pp. 322-325). St. Petersburg, Russia. 
Proshina, E. (2021). When it's all over: Russians refuse higher education. https://news.rambler.ru/community/ 46039691-kogda-eto-vse-zakonchitsya-rossiyane-otkazyvayutsya-ot-vysshego-obrazovaniya/ ?utm_referrer=https\%3A\%2F\%2Fzen.yandex.com

Rozanova, N. M. (2020). Transformation of higher education: Key patterns and long-term trends. Bulletin of the Institute of Economics of the Russian Academy of Sciences, 5, 64-78.

Sanders, A. (2017). An introduction to Unreal Engine 4. CRC Press. https://doi.org/10.1201/9781315382555

Sayapina, T. S. (2020). Trends in teaching legal disciplines in higher school. Business and Design Review, 4, 14. Shaidurov, A. A. (2018). The application of the Unity physics engine for creating games. Postulate, 1, 156.

Sushchenko, A. D. (2016). The value of additional education for students in the view of teachers and course organizers. Debate, 6, 77-83.

Tazabekov, D. Y., \& Buzhinskaya, N. V. (2020). The application of the Unity environment for the development of training computer games. Trends in the Development of Science and Education, 58(2), 34-37. https://doi.org/10.18411/lj-02-2020-26

Tran, T. (2017). Unreal Engine 4 drawing tutorial. https://www.raywenderlich.com/663-unreal-engine-4blueprints-tutorial

Turpak, A. M. (2016). The analysis of the possibility of using computer games in education. Science Time, 11, 537-542.

Virvou, M., Katsionis, G., \& Manos, K. (2005). Combining software games with education: Evaluation of its educational effectiveness. Educational Technology \& Society, 8, 54-58.

Williamson, B. (2009). Computer games, schools, and young people. A report for educators on using games for learning. Futurelab. https://www.nfer.ac.uk/publications/FUTL27/FUTL27.pdf

Yadrovskaya, M. V. (2015). The means of modeling in computer technologies of training. Educational Technologies and Society, 18(2), 618-637

Yuzhakov, V. N., \& Efremov, A. A. (2018). Legal and organizational barriers to the digitalization of education in the Russian Federation. Russian Law: Education, Practice, Science, 6, 18-24. https://doi.org/10.34076/241027-09-2018-6-18-24 


\section{APPENDIX A}
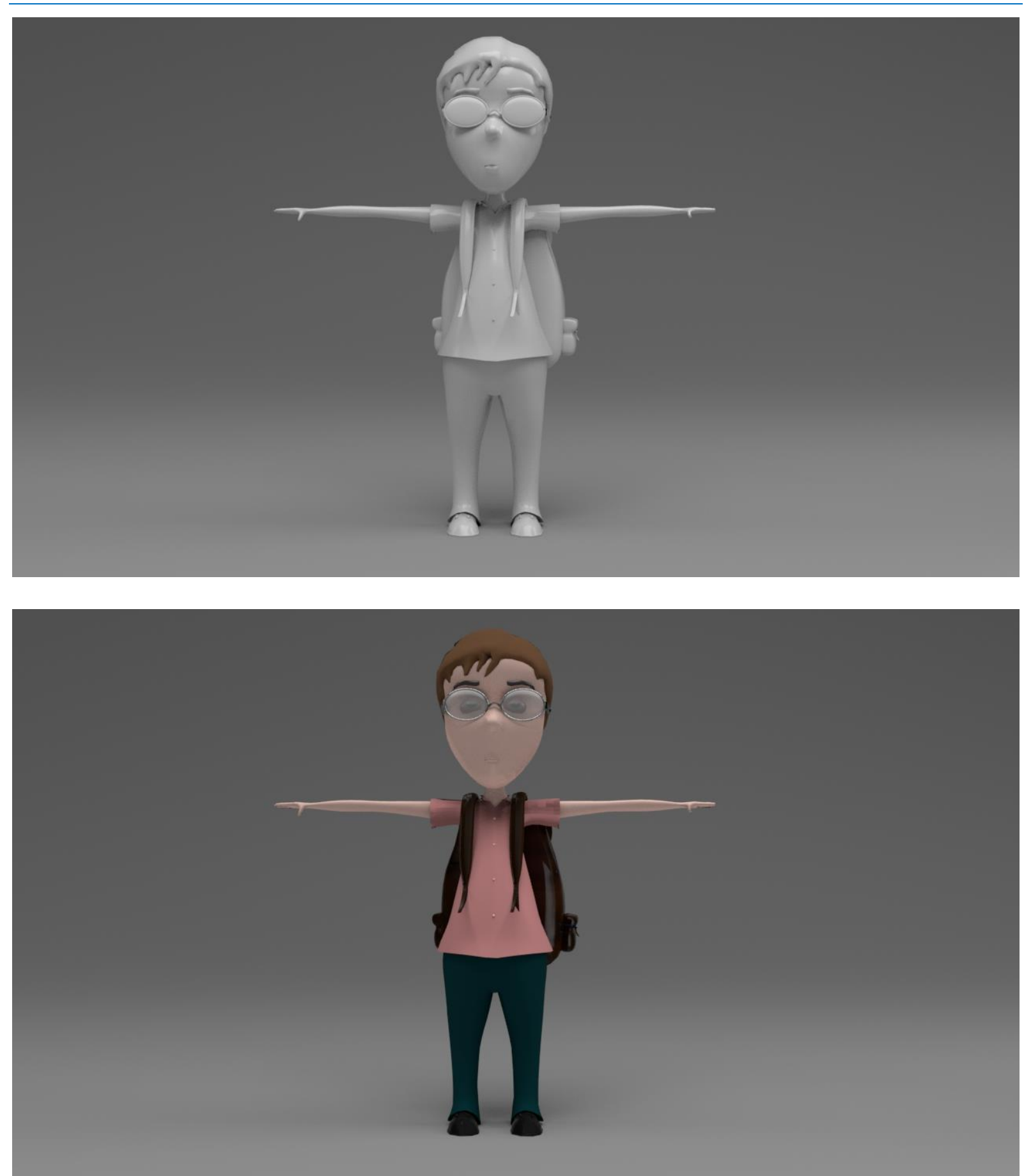


\section{APPENDIX B}
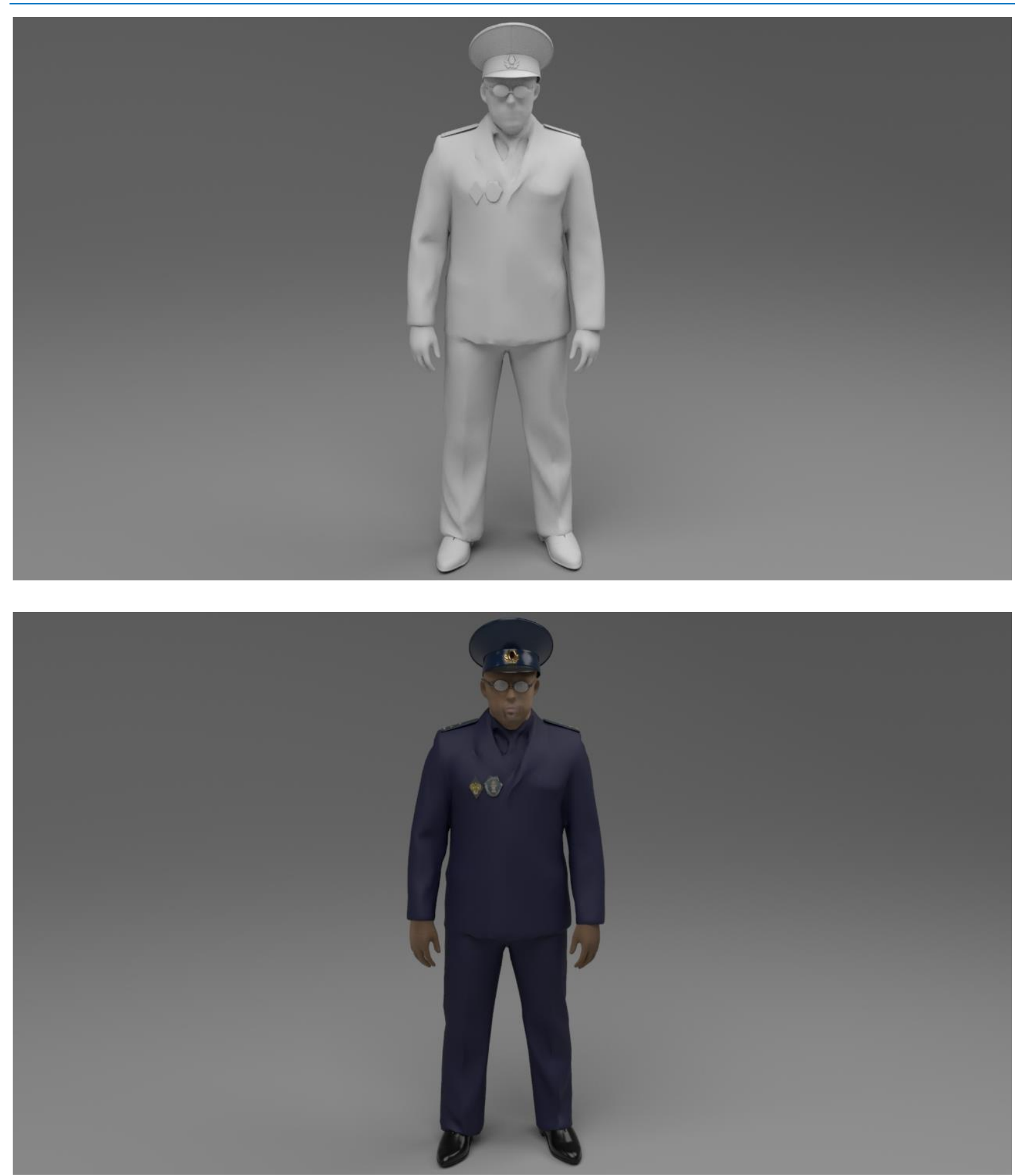


\section{APPENDIX C}

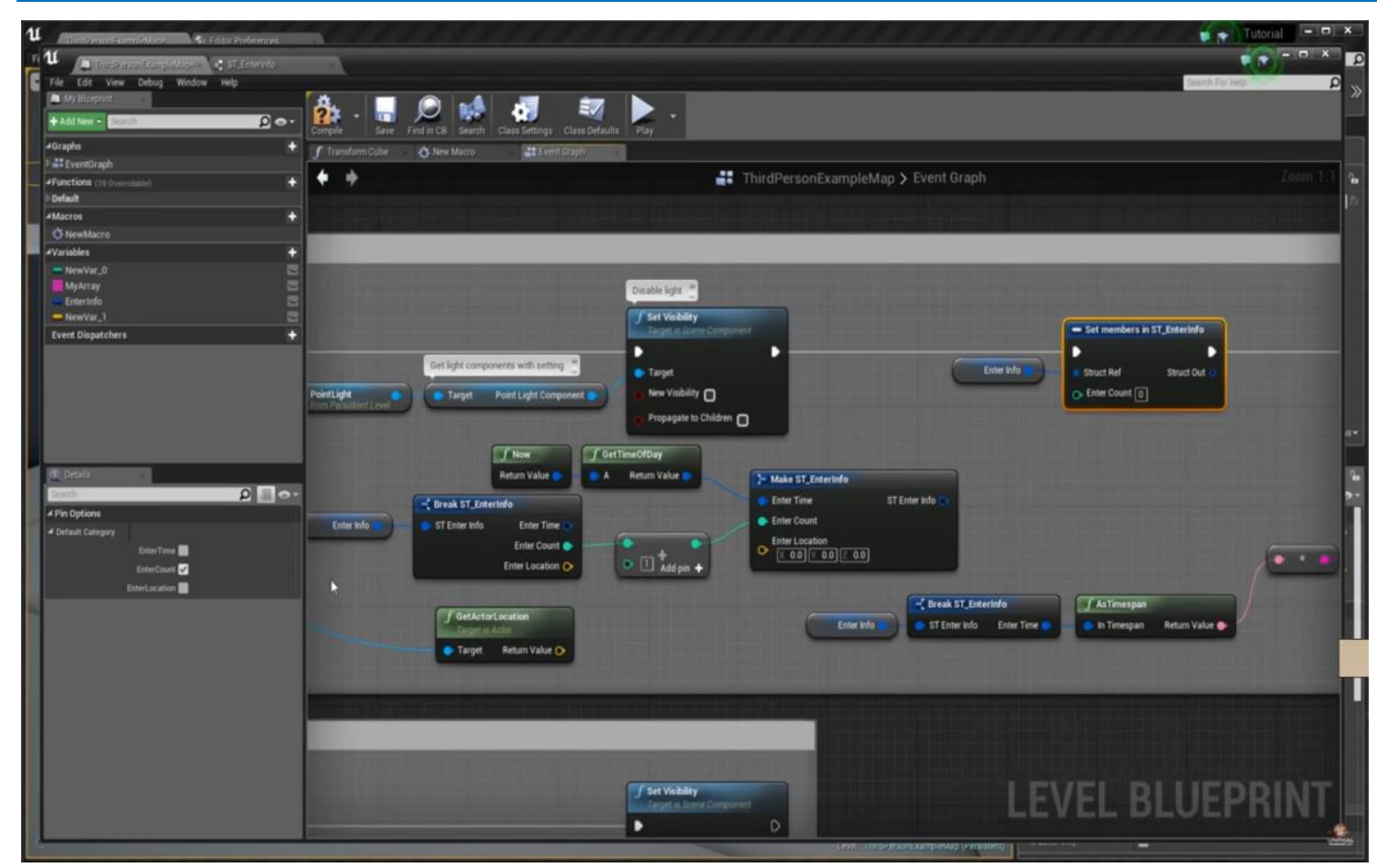




\section{APPENDIX D}

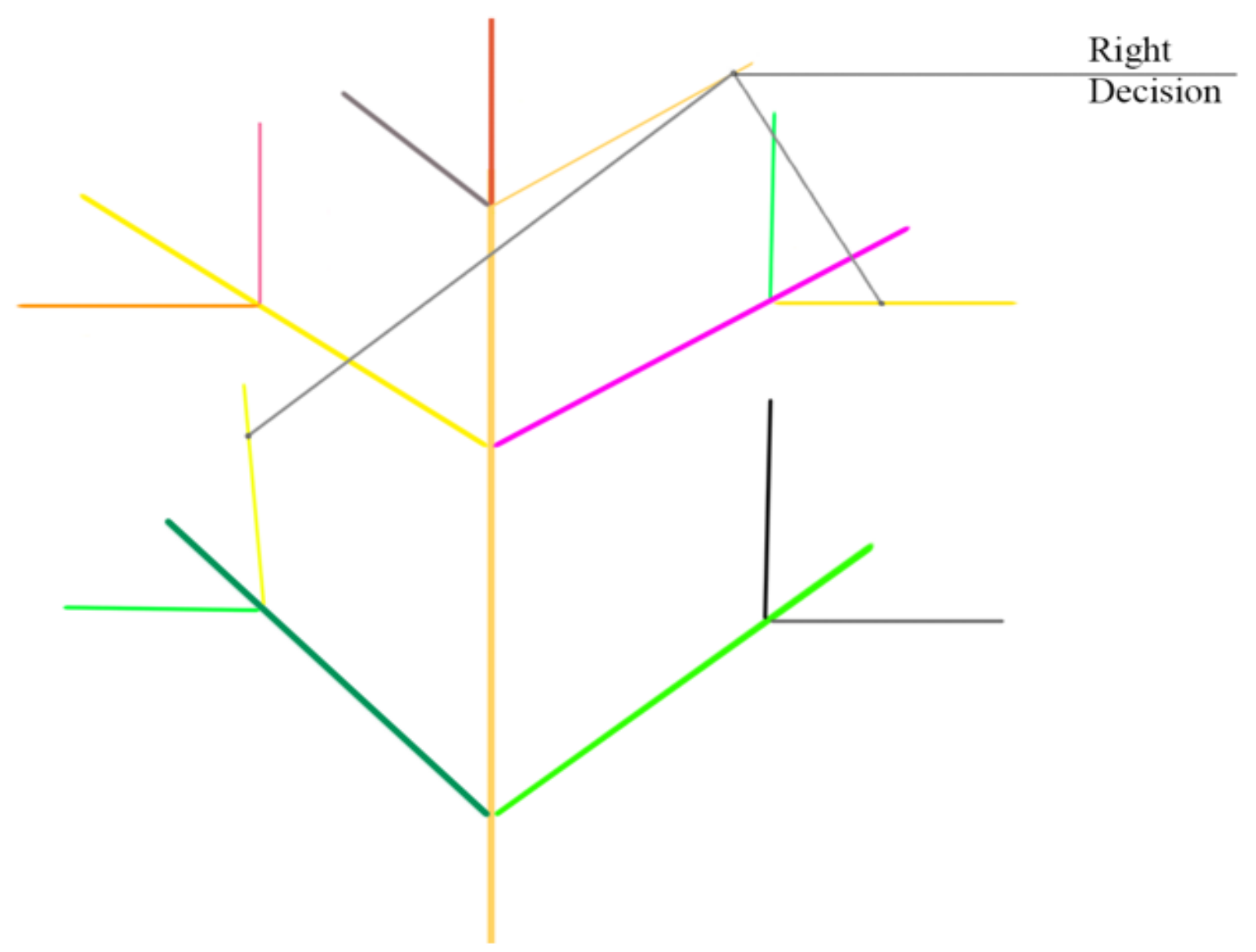

$\bullet$ 